\title{
Need Analysis: Portable Web Server DEVELOPMENT KITS FOR TEACHING AND LEARNING
}

\author{
Nor Masharah Husain, Nadia Akma Ahmad Zaki, Rasyidi Johan, and Noor Anida \\ Zaria Mohd Noor
}

Department of Computing, Faculty of Art, Computing \& Creative Industry, Universiti

Pendidikan Sultan Idris, Malaysia

\begin{abstract}
A Portable server is the combination of popular web server software, namely Apache, MySQL, PHP and PhpMyAdmin. With a portable server, users can develop and display a developed website anywhere at any time as all web server configurations have been installed on the storage drive. Portable servers are ideal for displaying the offline version of the website anywhere when developing a website. Using a mobile server as well, users do not need hosting that requires complicated configuration and can be used to run tests before putting the website online. This study aims to obtain preliminary findings on building portable web server development kits for the teaching and learning process.
\end{abstract}

\section{KEYWORDS}

Web Server, Portable Server, Portable Web Server, Web Development

\section{INTRODUCTION}

Web-based learning involves technological aids, such as computers, web server, internet access and suitable programming languages. The structure of learning in teacher-student centered has changed directly using online learning methods as a result of the pandemic Covid-19. These changes also affect the methods of learning and teaching in various subjects, including Computer Science. Due to the current situation, learning activities involving website development are difficult to carry out during online learning due to the factors involving the hardware and software required in website development process.

The website development process involves several areas of web engineering and multimedia applications that require a different set of skills and development processes [1]. Web development is the coding or programming that allows applications to be developed to be published in a web browser according to the requirements of the problem. There are two important parts to web development, namely front-end development (also called client development) and back-end development (also known as server development). Front-end development refers to building pages that are visible to users when they load a web application. This covers aspects of content maintenance, web design and how users interact with the web. This is done with three types of code namely HTML, CSS and JavaScript. The second part of the development is the back-end which is the server development. The back-end section serves to control what happens behind the web application page. Back-ends often use databases to generate web pages for users. Back-end coding is mostly written in specific coding languages and frameworks, such as PHP, Python, Ruby on Rails, ASP.NET, Perl, Java and so on to produce a complete website. 
The International Journal of Multimedia \& Its Applications (IJMA) Vol.13, No. 3, June 2021

Website development is the matter involved in developing a website for the internet (WWW) or an intranet (a private network) [2]. Web development can range from developing simple static pages from plain text to complete web-based internet applications (web applications), electronic businesses and social networking services. The web development process includes web design, web content development, and client-server coding configuration.

The website configuration process requires an important element that is a web server. A web server is server software or hardware assigned to run web software that can respond to customer requests from websites accessed from the WWW. The main function of a web server is to store, process and send websites to clients. Communication between client and server takes place using Hypertext Transfer Protocol (HTTP) [3]. The submitted page consists of an HTML document including images, style scripts and scripts, and textual content. The web server processes incoming network requests via HTTP and several other related protocols.

\section{BACKGROUND OF STUDY}

Server development involves a web server. Web servers often come as part of larger internet and intranet programs to handle email, download requests for File Transfer Protocol (FTP) files and build and display a website. Some web servers offer complete configuration packages, including Apache, Internet Information Server (IIS) and a database loaded into a computer [4].

A computer can test the functionality of a website developed to load all the necessary software [5]. The computer functions as a virtual server to display the website's result that has been developed offline (without involving the internet). Each computer has a network that can be accessed on a web browser that is localhost. Localhost refers to a computer that runs a program and is used to access network services running on that computer. This mechanism can be used to run network services on a host without the need for a physical network interface [6]. For example, a website installed on a computer can be accessed from a web browser with the URL http://localhost/webname/ to display the web page that has been developed.

Usually, website development activities are done in computer labs in schools with the help of teachers who teach. Computer technicians or teachers need to make settings or configurations on the computer to be equipped with software and applications that are suitable for web programming activities. However, the readiness and capability of a computer is a major factor in the failure to carry out website development activities. The server configuration also requires space to store server settings and all built -in website documents. Failure to provide a computer with the appropriate settings and configuration will complicate the server configuration process.

The process of maintaining a web server on a computer can be complicated if the user does not provide the necessary software in the ongoing installation or troubleshooting process. Users should also consider the suitability of each computer before the web server installation process is carried out. This will affect the usability and functionality of each web development that will be developed. Therefore, the researcher has planned to build a module and develop portable web server kits for teaching and learning to develop web applications.

\section{Methodology}

For the development process, it is very important to develop a particular model driven by research gaps in a particular field of study. This study was conducted using a structured survey study with 98 students randomly selected from various courses and programs at the university. Basically, the 
The International Journal of Multimedia \& Its Applications (IJMA) Vol.13, No. 3, June 2021

main purpose of this survey study is to explore and identify the need in developing portable web server kits for teaching and learning use that involves the development of web applications.

\subsection{Participants}

The selection of 98 students as respondents was made using a random sampling method. Researchers select respondents consisting of students who took courses related to web development and application development involving a group of students from the Computer Science, Software Engineering and Information Technology program. These respondents are also selected from a variety of educational backgrounds.

\subsection{Research Instrument}

Needs analysis in the educational process covers developments within the scope of certain objectives depending on research purposes [7]. This study's needs study was a survey questionnaire guided by the early literature related to teaching and web development learning. This instrument has two main parts. Section A contains items related to the demographics of the respondents. Part B includes three (3) sub-questions related to Level of Knowledge, Perception, and Level of Readiness respondents using portable web server kits for teaching and learning use that involves developing web applications.

Validation of the instrument was performed by two researchers who have experience in education and computer science. In the validation process, individual discussions were conducted to obtain expert opinions and suggestions on the questionnaire items in terms of clarity and appropriateness as well as construct validity. Basically, every feedback and suggestion are recorded and incorporated into the instrument to improve its reliability and quality.

\section{Data Analysis}

The needs analysis study was conducted through a survey using an online questionnaire. Survey to 98 students as respondents, consisting of students from different educational backgrounds and programs. The researcher used a quantitative approach to analyse the data based on the frequency and percentage that measured using Likert Scale 1 to 5 ranging from strongly disagree to strongly agree of each questionnaire item using SPSS software. These statistical measures help highlight and emphasize the need to build portable web server kits for teaching and learning practise.

\section{RESUlt AND DisCUSSION}

\subsection{First Findings: Level of Knowledge}

The first group of questions of the study of the needs is related to the respondents' level of knowledge about portable web servers. Directly, this question helps to highlight the level of knowledge of respondents on website development. Table 1 summarizes the results of the knowledge level items identified in this survey study. 
The International Journal of Multimedia \& Its Applications (IJMA) Vol.13, No. 3, June 2021

Table 1. Level of Knowledge Result

\begin{tabular}{|l|c|c|c|c|c|c|}
\hline \multicolumn{1}{|c|}{ Items } & $\mathbf{N}$ & SD & $\mathbf{D}$ & $\mathbf{N}$ & $\mathbf{A}$ & SA \\
\cline { 3 - 7 } & & $\boldsymbol{n}(\mathbf{\%})$ & $\boldsymbol{n}(\mathbf{\%})$ & $\boldsymbol{n}(\boldsymbol{\%})$ & $\boldsymbol{n}(\boldsymbol{\%})$ & $\boldsymbol{n}(\boldsymbol{\%})$ \\
\hline $\begin{array}{l}\text { I know about Portable Web Server } \\
\text { before }\end{array}$ & 98 & $\begin{array}{c}18 \\
(18.4 \%)\end{array}$ & $\begin{array}{c}18 \\
(18.4 \%)\end{array}$ & $\begin{array}{c}38 \\
(38.8 \%)\end{array}$ & $\begin{array}{c}16 \\
(16.3 \%)\end{array}$ & $8(8.2 \%)$ \\
\hline $\begin{array}{l}\text { I have used Portable Web Server } \\
\text { before }\end{array}$ & 98 & $\begin{array}{c}21 \\
(21.4 \%)\end{array}$ & $\begin{array}{c}25 \\
(25.5 \%)\end{array}$ & $\begin{array}{c}21 \\
(21.4 \%)\end{array}$ & $\begin{array}{c}21 \\
(21.4 \%)\end{array}$ & $\begin{array}{c}10 \\
(10.2 \%)\end{array}$ \\
\hline $\begin{array}{l}\text { I am good at using Portable Web } \\
\text { Server }\end{array}$ & 98 & $\begin{array}{c}18 \\
(18.4 \%)\end{array}$ & $\begin{array}{c}16 \\
(16.3 \%)\end{array}$ & $\begin{array}{c}42 \\
(42.9 \%)\end{array}$ & $\begin{array}{c}16 \\
(16.3 \%)\end{array}$ & $6(6.1 \%)$ \\
\hline I often use Portable Web Server & 98 & $\begin{array}{c}19 \\
(19.4 \%)\end{array}$ & $\begin{array}{c}23 \\
(23.5 \%)\end{array}$ & $\begin{array}{c}26 \\
(26.5 \%)\end{array}$ & $\begin{array}{c}19 \\
(19.4 \%)\end{array}$ & $\begin{array}{c}11 \\
(11.2 \%)\end{array}$ \\
\hline
\end{tabular}

Basic knowledge of respondents should be obtained to know the current level of knowledge about portable web servers. Almost all respondents do not know and have never used portable web servers. These findings support researchers to explore further areas related to the development of portable web servers.

\subsection{Second Findings: Perception}

The second sub of the needs analysis survey question focused on respondents' perceptions of creating a portable web server. The findings from this second sub-question will help provide a clear picture of the views and willingness of respondents to use portable web server in the future.

Table 2. Perception Result

\begin{tabular}{|c|c|c|c|c|c|c|}
\hline \multirow[t]{2}{*}{ Items } & \multirow[t]{2}{*}{$\mathbf{N}$} & SD & D & $\mathbf{N}$ & A & SA \\
\hline & & $n(\%)$ & $n(\%)$ & $n(\%)$ & $n(\%)$ & $n(\%)$ \\
\hline $\begin{array}{l}\text { The use of Portable Web Server will } \\
\text { facilitate the teaching and learning } \\
\text { process }\end{array}$ & 98 & 0 & 0 & $\begin{array}{c}25 \\
(25.5 \%)\end{array}$ & $\begin{array}{c}37 \\
(37.8 \%)\end{array}$ & $\begin{array}{c}36 \\
(36.7 \%)\end{array}$ \\
\hline $\begin{array}{l}\text { The use of Portable Web Server will } \\
\text { accelerate the achievement of learning } \\
\text { objectives }\end{array}$ & 98 & 0 & 0 & $\begin{array}{c}23 \\
(23.5 \%)\end{array}$ & $\begin{array}{c}45 \\
(45.9 \%)\end{array}$ & $\begin{array}{c}29 \\
(29.6 \%)\end{array}$ \\
\hline $\begin{array}{l}\text { The use of Portable Web Server is } \\
\text { relevant to use in the teaching and } \\
\text { learning process }\end{array}$ & 98 & 0 & 0 & $\begin{array}{c}18 \\
(18.4 \%)\end{array}$ & $\begin{array}{c}46 \\
(46.9 \%)\end{array}$ & $\begin{array}{c}34 \\
(34.7 \%)\end{array}$ \\
\hline $\begin{array}{l}\text { The use of a Portable Web Server will } \\
\text { improve the quality of my learning }\end{array}$ & 98 & 0 & $\begin{array}{c}1 \\
(1 \%)\end{array}$ & $\begin{array}{c}22 \\
(22.4 \%)\end{array}$ & $\begin{array}{c}46 \\
(46.9 \%)\end{array}$ & $\begin{array}{c}29 \\
(29.6 \%)\end{array}$ \\
\hline $\begin{array}{l}\text { The use of a Portable Web Server will } \\
\text { increase my productivity as a web } \\
\text { developer }\end{array}$ & 98 & 0 & $\begin{array}{c}2 \\
(2 \%)\end{array}$ & $\begin{array}{c}19 \\
(19.4 \%)\end{array}$ & $\begin{array}{c}48 \\
(49 \%)\end{array}$ & $\begin{array}{c}29 \\
(29.6 \%)\end{array}$ \\
\hline $\begin{array}{l}\text { The use of a Portable Web Server will } \\
\text { save time for the website configuration } \\
\text { process }\end{array}$ & 98 & 0 & $\begin{array}{c}2 \\
(2 \%)\end{array}$ & $\begin{array}{c}29 \\
(29.6 \%)\end{array}$ & $\begin{array}{c}42 \\
(42.9 \%)\end{array}$ & $\begin{array}{c}25 \\
(25.5 \%)\end{array}$ \\
\hline $\begin{array}{l}\text { The use of Portable Web Server will } \\
\text { can increase the effectiveness of } \\
\text { website development activities }\end{array}$ & 98 & 0 & 0 & $\begin{array}{c}28 \\
(28.6 \%)\end{array}$ & $\begin{array}{c}41 \\
(41.8 \%)\end{array}$ & $\begin{array}{c}29 \\
(29.6 \%)\end{array}$ \\
\hline $\begin{array}{l}\text { The use of a Portable Web Server will } \\
\text { facilitate the technical management } \\
\text { activities of computer labs }\end{array}$ & 98 & 0 & $\begin{array}{c}2 \\
(2 \%)\end{array}$ & $\begin{array}{c}24 \\
(24.5 \%)\end{array}$ & $\begin{array}{c}42 \\
(42.9 \%)\end{array}$ & $\begin{array}{c}30 \\
(30.6 \%)\end{array}$ \\
\hline
\end{tabular}

The second finding is about students' perceptions of the usage of portable web servers. Most respondents agreed with the statement regarding the uses and advantages of using a portable web 
server in web development activities. The use of portable web servers is also able to increase productivity and quality in the learning process of website development.

\subsection{Third Findings: Level of Readiness}

The third questionnaire of the survey discusses the findings on students' readiness to use Portable Web server in the teaching and learning process later. Table 3 shows a list of questionnaires answered by the respondents and the findings obtained for the overall level of readiness in the use of portable web server.

Table 3. Level of Readiness Result

\begin{tabular}{|c|c|c|c|c|c|c|}
\hline \multirow[t]{2}{*}{ Items } & \multirow[t]{2}{*}{$\mathbf{N}$} & SD & D & $\mathbf{N}$ & A & SA \\
\hline & & $n(\%)$ & $\begin{array}{c}n \\
(\%)\end{array}$ & $n(\%)$ & $n(\%)$ & $n(\%)$ \\
\hline $\begin{array}{l}\text { I am confident that using Portable Web } \\
\text { Server can improve the quality in website } \\
\text { development }\end{array}$ & 98 & 0 & 0 & $\begin{array}{c}32 \\
(32.7 \%)\end{array}$ & $\begin{array}{c}33 \\
(33.7 \%)\end{array}$ & $\begin{array}{c}33 \\
(33.7 \%)\end{array}$ \\
\hline $\begin{array}{l}\text { I will use Portable Web Server to } \\
\text { facilitate the website development } \\
\text { process }\end{array}$ & 98 & 0 & $\begin{array}{c}2 \\
(2 \%)\end{array}$ & $\begin{array}{c}26 \\
(26.5 \%)\end{array}$ & $\begin{array}{c}36 \\
(36.7 \%)\end{array}$ & $\begin{array}{c}34 \\
(34.7 \%)\end{array}$ \\
\hline $\begin{array}{l}\text { I plan to use Portable Web Server in } \\
\text { every website project development }\end{array}$ & 98 & 0 & 0 & $\begin{array}{c}32 \\
(32.7 \%)\end{array}$ & $\begin{array}{c}33 \\
(33.7 \%)\end{array}$ & $\begin{array}{c}32 \\
(32.7 \%)\end{array}$ \\
\hline $\begin{array}{l}\text { I would encourage other friends to use } \\
\text { Portable Web Server }\end{array}$ & 98 & 0 & $\begin{array}{c}1 \\
(1 \%) \\
\end{array}$ & $\begin{array}{c}24 \\
(24.5 \%) \\
\end{array}$ & $\begin{array}{c}36 \\
(36.7 \%) \\
\end{array}$ & $\begin{array}{c}37 \\
(37.8 \%) \\
\end{array}$ \\
\hline
\end{tabular}

Findings from the level of readiness show that more than half of the respondents are ready to use portable web servers in the future. The findings from these four questions convinced researchers to continue exploring the development of portable web servers.

\section{CONClusion}

Undoubtedly, needs analysis can help highlight current issues related to portable web servers in web development activities. As shown in this study, most respondents are not knowledgeable in the use of portable web servers. In fact, some of them have never applied the portable web server during the study period. Therefore, the researchers conducted a needs analysis survey involving a group of students from Computer Science and Information Technology programs to obtain important information that helps determine the needs in the future development of portable web servers. Hence, a proposal to develop portable web server development kits for teaching and learning is able to give a positive impact in the learning process independently. the kits produced can be used by teachers and students in schools, as well as at the university level.

\section{ACKNOWLEDGEMENTS}

This research was supported by Universiti Pendidikan Sultan Idris through University Research Grant (GGPU/2020-0022-106-01).

\section{REFERENCES}

[1] Manhas, J. (2017). Initial framework for website design and development. International Journal of Information Technology, 9, 363-375.

[2] Campbell, J (2017). Web Design: Introductory. Cengage Learning. 
The International Journal of Multimedia \& Its Applications (IJMA) Vol.13, No. 3, June 2021

[3] Patrick, Killelea (2002). Web performance tuning (2nd ed.). Beijing: O'Reilly. ISBN 059600172X.

[4] Halsey, M (2016). Windows 10 Troubleshooting. Springer. Sheffield, South Yorkshire, UK.

[5] Corley, C. S., Lois, F., \& Quezada, S. (2015). Web usage patterns of developers. 2015 IEEE International Conference on Software Maintenance and Evolution (ICSME). doi:10.1109/icsm.2015.7332489.

[6] Paessler AG. Server - How a server works. Retrieved from https://www.paessler.com/support/itknowledge/it-explained/server

[7] Sönmez, Hülya. (2019). An Examination of Needs Analysis Research in the Language Education Process. International Journal of Education and Literacy Studies. 7 (1). doi: 10.7575/aiac.ijels

\section{AUTHORS}

Nor Masharah Husain is a senior lecturer at the Computing Department, Faculty of Art, Computing and Creative Industry, Universiti Pendidikan Sultan Idris (UPSI). She has graduated her Ph.D of Information Technology in Education in 2017. Her expertise is in the field of educational technology. She also interested in the field of Interactive Learning, Multimedia and Mobile Learning, as well as Web Development in educational purpose.

Nadia Akma Ahmad Zaki is a lecturer at the Computing Department, Faculty of Art, Computing and Creative Industry, Universiti Pendidikan Sultan Idris (UPSI). Received her Master of Science, Computer Science in 2006. Her specialization is in Multimedia and interested in the field of Serious Games, Augmented and Virtual Reality, Multimedia and Education, Digital Media, Computer Graphics, M-Learning, E-Learning, and Simulation.

Rasyidi Johan is a lecturer at the Computing Department, Faculty of Art, Computing and Creative Industry, Universiti Pendidikan Sultan Idris (UPSI). He is now Deputy Director (Alumni Centre) at UPSI. His field of specialization is in Information Technology. His research interests focus on Multimedia Courseware Design and Development, Web Based Personalize Learning Application, Framework Design for Learning Environment and Artificial Intelligence.

Noor Anida Zaria Mohd Noor is a Senior lecturer at the Computing Department, Faculty of Art, Computing and Creative Industry, Universiti Pendidikan Sultan Idris (UPSI). She is now Deputy Director at Entrepreneurship Development \& Graduate Employability Centre, UPSI. Her research interests related to Information Technology, Database Management, Entrepreneurship, Knowledge Management (Knowledge Integration) and Management Information System.
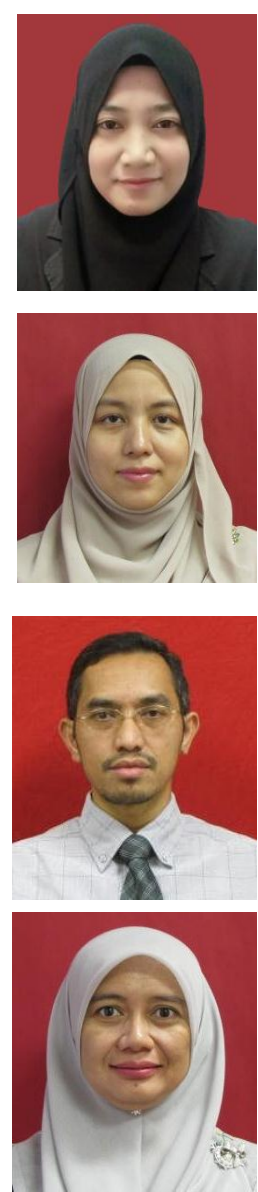